\title{
Quantitative contrast-enhanced CT attenuation evaluation of osseous metastases following chemotherapy
}

\section{Citation}

Chang, Connie Y., F. Joseph Simeone, Martin Torriani, and Miriam A. Bredella. 2017. "Quantitative Contrast-Enhanced CT Attenuation Evaluation of Osseous Metastases

Following Chemotherapy." Skeletal Radiology 46 (10) (June 30): 1385-1395. doi:10.1007/ s00256-017-2706-6.

\section{Published Version}

doi:10.1007/s00256-017-2706-6

\section{Permanent link}

http://nrs.harvard.edu/urn-3:HUL.InstRepos:34917376

\section{Terms of Use}

This article was downloaded from Harvard University's DASH repository, and is made available under the terms and conditions applicable to Other Posted Material, as set forth at http:// nrs.harvard.edu/urn-3:HUL.InstRepos:dash.current.terms-of-use\#LAA

\section{Share Your Story}

The Harvard community has made this article openly available.

Please share how this access benefits you. Submit a story.

Accessibility 
Title: QUANTITATIVE CT DENSITY EVALUATION OF OSSEOUS METASTASES FOLLOWING CHEMOTHERAPY

Authors: Connie Y. Chang, MD, F. Joseph Simeone, MD, Martin Torriani, MD, Miriam A.

Bredella, MD 


\section{ABSTRACT}

Purpose: Osseous metastases often undergo an osteoblastic response following chemotherapy also known as the "flare" phenomenon. The purpose of our study was to demonstrate the quantitative CT changes in density of osseous metastases before and after chemotherapy.

Materials and Methods: Our study was IRB approved and HIPAA compliant. Our cohort consisted of 48 consecutive cancer patients with studies both before chemotherapy/at the time of diagnosis of osseous metastases and $14 \pm 3$ (12-20) months after the initiation of treatment 60 \pm 10 (range: $37-80$ ) years, $26 \mathrm{~F}, 22 \mathrm{M}$ ). CT density of all lesions was measured by two fellowship trained MSK radiologists. The largest possible region of interest was selected to measure the average and maximum densities in Hounsfield Units (HU). If multiple lesions were present, the largest lesion was evaluated. Treatment effects were assessed using paired $t$-tests, using $\mathrm{P}<0.05$ as statistically significant. Intraclass correlation coefficient (ICC) was calculated for the two readers.

Results: The distribution of primary tumors was as follows: breast (20/48, 42\%), lung (10/48, $21 \%)$, prostate $(5 / 48,10 \%)$, pancreatic $(5 / 48,10 \%)$, renal $(2 / 48,4 \%)$, and other $(6 / 48,13 \%)$. The measured lesions were in the following locations: spine/sacrum $(35 / 48,73 \%)$, pelvis $(10 / 48$, $21 \%)$, sternum $(3 / 48,6 \%)$. The distribution of lesion types were as follows: lytic $(14 / 48,29 \%)$, blastic (25/48, 52\%), and mixed lytic-blastic (9/48, 19\%). Mean and maximum CT densities (Reader 1) of all metastases before chemotherapy treatment were $328 \pm 206 \mathrm{HU}$ and $580 \pm 391$ $\mathrm{HU}$, respectively and after chemotherapy treatment were $511 \pm 263 \mathrm{HU}$ and $789 \pm 439 \mathrm{HU}$, respectively. There was a significant increase in mean and maximum CT densities of metastases following chemotherapy for all lesions collectively but also when separated into lytic, blastic, and mixed lytic-blastic lesions $(\mathrm{P}<0.05)$. ICC was almost perfect for average density and moderate to substantial for maximum density.

Conclusion: Quantitative assessment of osseous metastatic disease using CT density measurements confirms a statistically significant increase in density 12-20 months after initiation of chemotherapy.

Clinical Application: Measuring changes in CT density of osseous metastases may have a significant role in evaluating chemotherapy effect. 


\section{INTRODUCTION}

Osseous metastatic disease is common, affecting approximately 280,000 adults in the United States, and with approximately $68 \%$ of cases occurring in patients with primary breast, prostate, or lung cancer. Accurate evaluation of the imaging findings of osseous metastatic disease is important for staging, outcome prediction, and treatment planning [1-5].

Osseous metastases often undergo an osteoblastic response following chemotherapy also known as the "flare phenomenon." Initially observed in skeletal scintigraphy, a discordance between apparent clinical improvement of the patient and unexpected additional bony lesions with greater Technetium-99m-methylene diphosphonate uptake, was thought to reflect a healing response to the chemotherapy [6-11]. A similar response has been seen in CT density of metastases where an increase in density may considered to be a positive response to treatment [5]. Although this has been demonstrated qualitatively, it has not been proven with a systematic study of a cohort. Therefore, it is not known if this difference is statistically significant and consistently reproducible. Also, the numeric values associated with the densities before and after chemotherapy and the change in density is not known.

The purpose of our study was to demonstrate the quantitative CT changes in density of osseous metastases before and after chemotherapy.

\section{MATERIALS AND METHODS \\ Patient Cohort}

Our study was IRB approved and HIPAA compliant. Inclusion criteria were age $\geq 18$ years, history of cancer, presence of osseous metastases, and contrast-enhanced CT of the chest, abdomen and pelvis before chemotherapy as well as 12 or more months after the initiation of chemotherapy treatment.

\section{CT Technique}

Lesions were evaluated using either a 16 or 64-slice CT (Siemens Biograph 16 or 64, Siemens, Erlangen, Germany or GE Healthcare discover, Milwaukee, Wisconsin, USA).

All metastatic lesions were identified and evaluated on either a CT of the chest or a CT of the abdomen and pelvis (slice thickness, $2.5 \mathrm{~mm}$ for chest and $5 \mathrm{~mm}$ for abdomen/pelvis; table 
feed, $15 \mathrm{~mm} / \mathrm{sec}$; pitch 1.5; tube voltage, $120 \mathrm{kVP}$; tube current, $200 \mathrm{mAs}$; sagittal and coronal reconstruction thickness, $2 \mathrm{~mm}$ with $2 \mathrm{~mm}$ intervals) with IV and oral contrast.

\section{Density Measurements}

Density measurements were performed on a Picture Archiving and Communication System (PACS) workstation (Agfa, Morstel, Belgium) by two musculoskeletal radiologists with 5 and 4 years of experience.

The $\mathrm{CT}$ of the chest, abdomen and pelvis was reviewed, and the largest lesion on axial slices was selected. The round region of interest (ROI) tool was used to draw the largest possible ROI over the lesion without extending beyond lesion margins or including an adjacent cortex to measure the average density in Hounsfield Units (HU). The same slice was used to measure the maximum density using the square histogram tool. If necessary, the square was permitted to extend beyond the margins of the lesion while excluding any adjacent cortex. The histogram tool provided the range of densities and the number of pixels for each density value. The maximum density in HU was recorded.

The lesion location was provided to the second observer to perform the measurements, but all measurements were performed independently by the two readers. The type of lesion (lytic, blastic, mixed lytic-blastic) and the patient's overall disease status in terms of CT and clinical follow-up based on patient notes were recorded.

\section{Statistical Analysis}

The means and standard deviations for each patient's largest lesion were calculated, and groups were compared using the Student's $t$-test (JMP, version 12 Pro, SAS Institute, Cary, NC). $\mathrm{P}<0.05$ was considered statistically significant. Interreader reproducibility was assessed using intraclass correlation coefficient (ICC) with 95\% confidence interval (CI) (MedCalc Statistical Software version 16.4.3, Ostend, Belgium). ICC value of 0-0.2 indicated slight agreement, 0.210.40 indicated fair agreement, $0.41-0.60$ indicated moderate agreement, $0.61-0.80$ indicated substantial agreement, and 0.81-1.0 indicated almost perfect agreement.

\section{RESULTS}

Patient Cohort 
The patient cohort consisted of 48 patients, with 22 (46\%) males and 26 (54\%) females, ages $60 \pm 10$ (range 37-80) years. The distribution of primary tumors was as follows: breast (20/48, 42\%), lung $(10 / 48,21 \%)$, prostate $(5 / 48,10 \%)$, pancreatic pancreas $(5 / 48,10 \%)$, renal $(2 / 48,4 \%)$, and other (liver, bladder, kidney, rectum, esophagus, melanoma) $(6 / 48,13 \%)$. The average time between CT studies was $14 \pm 3$ months, with a range of 12 to 26 months.

The measured lesions were in the following locations: spine/sacrum $(35 / 48,73 \%)$, pelvis $(10 / 48,21 \%)$, sternum $(3 / 48,6 \%)$. The distribution of lesion types were as follows: lytic (14/48, $29 \%)$, blastic $(25 / 48,52 \%)$, and mixed lytic-blastic $(9 / 48,19 \%)$.

\section{CT Density of Metastatic Lesions}

The average and maximum CT densities of all metastases before and after chemotherapy for both readers are detailed in Table 1 and Table 2. There was a significant increase in average and maximum CT densities of metastases following chemotherapy for lytic (Figure 1), blastic (Figure 2), and mixed lytic-blastic (Figure 3) metastases. The increase in average density (Reader 1) was $183 \pm 220 \mathrm{HU}$ for all lesions, $159 \pm 193 \mathrm{HU}$ for lytic lesions, and $159 \pm 208 \mathrm{HU}$ for blastic lesions, and $287 \pm 279 \mathrm{HU}$ for mixed lytic-blastic lesions. The increase in maximum density was $209 \pm 278 \mathrm{HU}$ for all lesions, $230 \pm 325 \mathrm{HU}$ for lytic lesions, and $143 \pm 215 \mathrm{HU}$ for blastic lesions, and $369 \pm 325 \mathrm{HU}$ for mixed lytic-blastic lesions.

There was a subgroup of 9/48 (19\%) patients whose osseous metastases decreased in average density. The distribution of lesion types were as follows: lytic (3/9, 33\%), blastic (4/9, $44 \%$ ) (Figure 4), and mixed lytic-blastic (2/9, 22\%). There was no significant difference in the distribution of lesion type between patients whose metastases increased or decreased in density $(\mathrm{P}=0.7)$. In the patients with a decrease in density, an overall progression of disease (primary tumor or metastatic disease) was seen in 6/9 (67\%), improvement of disease was seen in 0/9 $(0 \%)$, and stable disease was seen in 3/9 (33\%). In the patients with an increase in lesion density, an overall progression of disease was seen in 20/39 (51\%) patients; in 4/39 (10\%) patients' disease improved and in 15/39 (38\%) patients' disease was stable. There was no statistically significant difference between these groups $(\mathrm{P}=0.8)$.

The ICC for Reader 1 and Reader 2's average density measurements was 0.83 (95\% CI, 0.0.71-0.90; almost perfect agreement) before chemotherapy and 0.97 (95\% CI, 0.97-0.98, almost perfect agreement). The ICC for Reader 1 and Reader 2's average density measurements 
was 0.42 (95\% CI, 0.16-0.63; moderate agreement) before chemotherapy and 0.65 (95\% CI, 0.0.45-0.79, substantial agreement).

\section{DISCUSSION}

Our quantitative assessment of osseous metastases using CT density measurements confirms a statistically significant increase in density more than 12 months after initiation of chemotherapy.

Pollen et al initially described osteoblastic response after chemotherapy as an increase in number and sclerosis of metastases in patients with prostate cancer on radiography without corresponding increased uptake on bone scan [12]. A bone scan "flare" phenomenon has also been described, where follow up bone scans showed "new" lesions, which was contradictory to overall clinical improvement of the patient's oncologic status, and subsequent clinical and imaging follow up confirmed regression of the patient's disease [7,8]. A similar finding has also been described with positron emission tomography (PET) in gastric cancer patients [13-15]. Stattaus et al demonstrated an osteoblastic response with an average increase in CT density of $153 \mathrm{HU}$ in a series of 24 patients with small cell lung cancer patients. However, CT density measurements were only performed in the 15 patients who demonstrated an increase in number of metastases [16]. Similar qualitative studies were also performed for prostate, gastric, and small cell lung cancer patients [14,16,17]. Quattrocchi et al demonstrated a quantitative increase of CT density in lytic and sclerotic metastases after 3 months of bisphosphonate (zoledronic acid) administration but did not study chemotherapeutic agents [18].

To our knowledge, no series has been performed to evaluate the quantitative changes of CT density after chemotherapy administration. When evaluating osseous lesions on follow up CT examinations, the results of this study confirm that the increase in density can be interpreted as an effect of the chemotherapy, especially in the setting of overall clinical improvement. We explored a temporal relationship between the initiation of chemotherapy and a change in the CT density of osseous metastases. Our observed increase in CT density following chemotherapy is consistent with the prior studies showing increased CT density following therapy. Questions to be explored include temporal relationship of CT density changes following therapy. We picked one year as the minimum duration of follow-up in order to capture changes in CT density. The 
change in density likely occurs much earlier. In the study by Quattrocchi et al, an increase in CT density was detected after 3 months of therapy [18]. Our observed decrease in CT density of some lesions also poses interesting questions. We explored the possibility that the lesion type (lytic, blastic, mixed lytic-blastic) or the patient's overall disease status may be a contributing factors of this change. Although we did not see a statistically significant difference between the groups, the number of lesions which decreased in density was small $(n=9)$. For our study we only measured the density of the largest lesion in each patient, but in a previous study done by the authors, we found that there was no significant variation in osseous metastasis density within the same patient

Limitations of our study include our retrospective nature, which precludes standardization of the chemotherapy regimen and the interval of the follow-up studies. A lower agreement between the readers in the measurement of the maximum density was observed, which may be related to the heterogeneity of treated lesions.

In conclusion, osseous metastatic disease on average increases in density before and after chemotherapy. Measuring changes in CT density of osseous metastases may have a significant role in evaluating chemotherapy response. 


\section{TABLES}

Table 1: Average densities

\begin{tabular}{|c|c|c|c|c|c|c|}
\hline & \multicolumn{3}{|c|}{ Reader 1} & \multicolumn{3}{|c|}{ Reader 2} \\
\hline $\begin{array}{l}\text { Lesion } \\
\text { Type }\end{array}$ & $\begin{array}{c}\text { Pre- } \\
\text { Chemotherapy } \\
\text { Density (HU) }\end{array}$ & $\begin{array}{c}\text { Post- } \\
\text { Chemotherapy } \\
\text { Density (HU) }\end{array}$ & $\mathbf{P}$ & $\begin{array}{c}\text { Pre- } \\
\text { Chemotherapy } \\
\text { Density (HU) }\end{array}$ & $\begin{array}{c}\text { Post- } \\
\text { Chemotherapy } \\
\text { Density (HU) }\end{array}$ & $\mathbf{P}$ \\
\hline All & $\begin{array}{l}328 \pm 206(23- \\
863)\end{array}$ & $\begin{array}{l}511 \pm 263(-7- \\
1047)\end{array}$ & $<0.0001$ & $\begin{array}{l}306 \pm 188(35- \\
800)\end{array}$ & $511 \pm 258(0-959)$ & $<0.0001$ \\
\hline Lytic & $117 \pm 73(23-240)$ & $\begin{array}{l}276 \pm 197(-7- \\
615)\end{array}$ & 0.01 & $1117 \pm 52(35-211)$ & $\begin{array}{l}272 \pm 203(35- \\
211)\end{array}$ & 0.02 \\
\hline Blastic & $\begin{array}{l}435 \pm 189(70- \\
863)\end{array}$ & $\begin{array}{l}594 \pm 247(56- \\
1047)\end{array}$ & 0.0006 & $\begin{array}{l}404 \pm 176(133- \\
800)\end{array}$ & $\begin{array}{l}609 \pm 232(58- \\
959)\end{array}$ & 0.0002 \\
\hline $\begin{array}{l}\text { Mixed } \\
\text { Lytic- } \\
\text { Blastic }\end{array}$ & $\begin{array}{l}323 \pm 147(84- \\
546)\end{array}$ & $\begin{array}{l}610 \pm 186(289- \\
911)\end{array}$ & 0.01 & $\begin{array}{l}298 \pm 133(66- \\
499)\end{array}$ & $\begin{array}{l}574 \pm 184(232- \\
783)\end{array}$ & 0.006 \\
\hline
\end{tabular}

Table 2: Maximum densities

\begin{tabular}{|c|c|c|c|c|c|c|}
\hline & \multicolumn{3}{|c|}{ Reader 1} & \multicolumn{3}{|c|}{ Reader 2} \\
\hline $\begin{array}{l}\text { Lesion } \\
\text { Type }\end{array}$ & $\begin{array}{l}\text { Pre- } \\
\text { Chemotherapy } \\
\text { Density (HU) }\end{array}$ & $\begin{array}{l}\text { Post- } \\
\text { Chemotherapy } \\
\text { Density (HU) }\end{array}$ & $\mathbf{P}$ & \begin{tabular}{|l} 
Pre- \\
Chemotherapy \\
Density (HU)
\end{tabular} & $\begin{array}{l}\text { Post- } \\
\text { Chemotherapy } \\
\text { Density (HU) }\end{array}$ & $\mathbf{P}$ \\
\hline All & $\begin{array}{l}580 \pm 391(128- \\
1744)\end{array}$ & $\begin{array}{l}789 \pm 439(108- \\
2176)\end{array}$ & $<0.0001$ & $\begin{array}{l}455 \pm 241(78- \\
869)\end{array}$ & $\begin{array}{l}707 \pm 289(145- \\
1202)\end{array}$ & $<0.0001$ \\
\hline Lytic & $\begin{array}{l}316 \pm 341(128- \\
1416)\end{array}$ & $\begin{array}{l}546 \pm 426(110- \\
1567)\end{array}$ & 0.03 & $208 \pm 70(78-333)$ & $\begin{array}{l}489-280(145- \\
972)\end{array}$ & 0.006 \\
\hline Blastic & $\begin{array}{l}600 \pm 221(144- \\
1068)\end{array}$ & $\begin{array}{l}743 \pm 262(108- \\
1230)\end{array}$ & 0.002 & $\begin{array}{l}555 \pm 209(225- \\
869)\end{array}$ & $\begin{array}{l}753 \pm 247(159- \\
1088)\end{array}$ & 0.0002 \\
\hline $\begin{array}{l}\text { Mixed } \\
\text { Lytic- } \\
\text { Blastic }\end{array}$ & $\begin{array}{l}905 \pm 581(263- \\
1744)\end{array}$ & $\begin{array}{l}1275 \pm 528(389 \\
2176)\end{array}$ & 0.009 & $\begin{array}{l}526 \pm 243(99- \\
862)\end{array}$ & $\begin{array}{l}890 \pm 247(431- \\
1202)\end{array}$ & 0.001 \\
\hline
\end{tabular}




\section{FIGURES:}
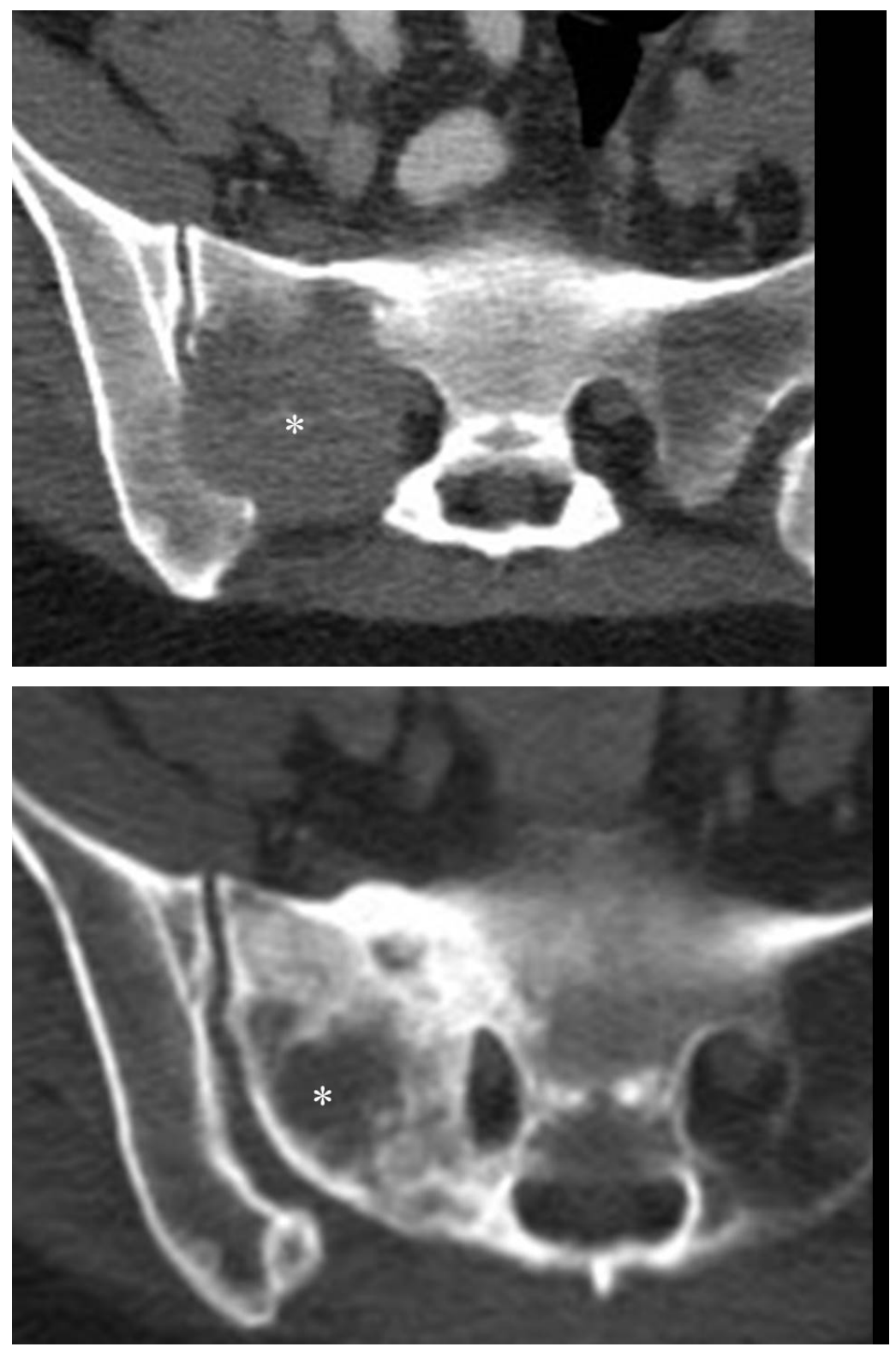

Figure 1: 50 year old woman with lung cancer. A) Axial contrast-enhanced CT at initial cancer diagnosis demonstrates a lytic osseous metastasis in the right sacrum $(*)$. The average density is $87 \mathrm{HU}$ and the maximum density is $304 \mathrm{HU} . \mathrm{B})$ Axial contrast-enhanced CT 13 months after initiation of chemotherapy demonstrates increased density of lytic osseous metastasis in the sacrum (*). The average density is $184 \mathrm{HU}$ and the maximum density is $975 \mathrm{HU}$. 

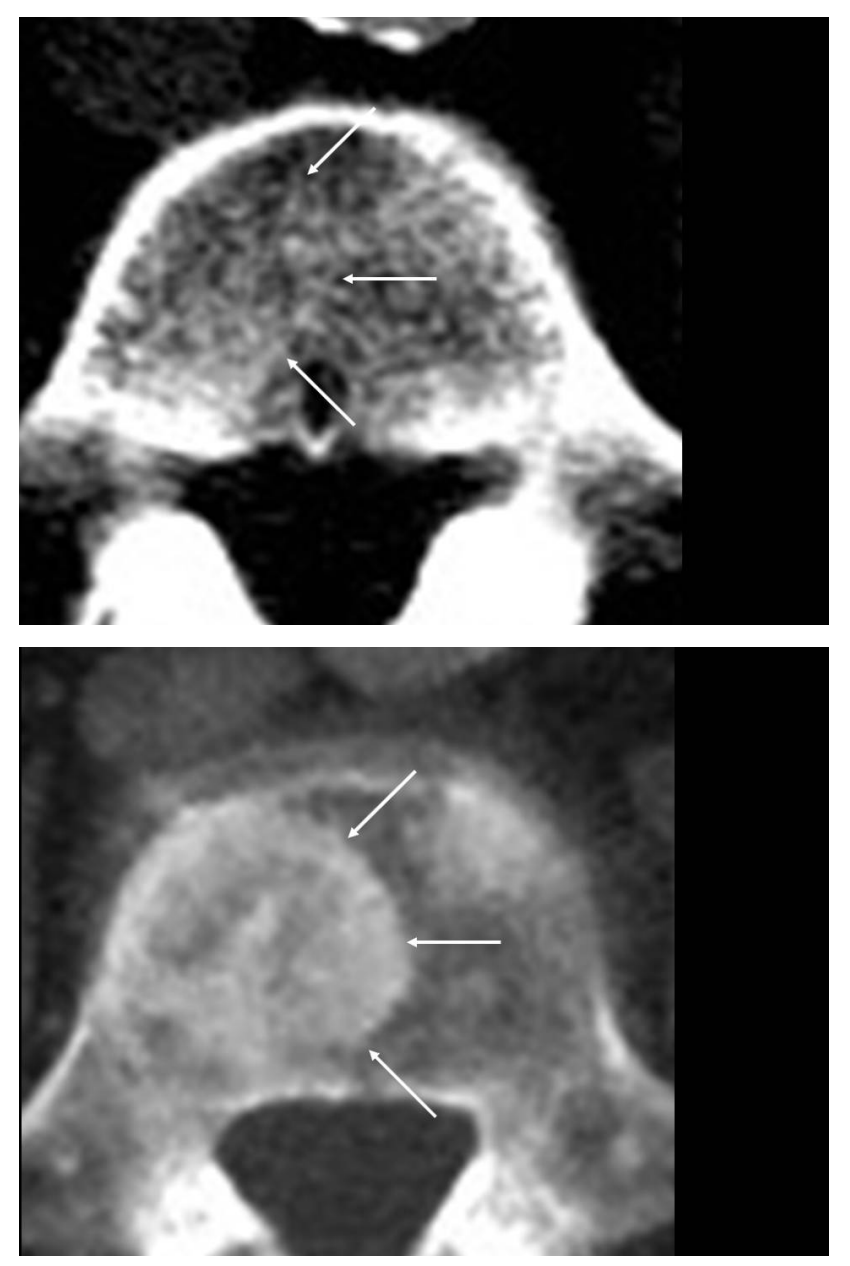

Figure 2. 72 year old man with prostate cancer. A) Axial contrast-enhanced CT at initial cancer diagnosis demonstrates a blastic osseous metastasis in the right half of the L5 vertebral body (arrows). The average density is $228 \mathrm{HU}$ and the maximum density is $459 \mathrm{HU}$. B) Axial contrastenhanced CT 14 months after initiation of chemotherapy demonstrates increased density of the blastic osseous metastasis in the L5 vertebral body (arrows). The average density is $473 \mathrm{HU}$ and the maximum density is $670 \mathrm{HU}$. 


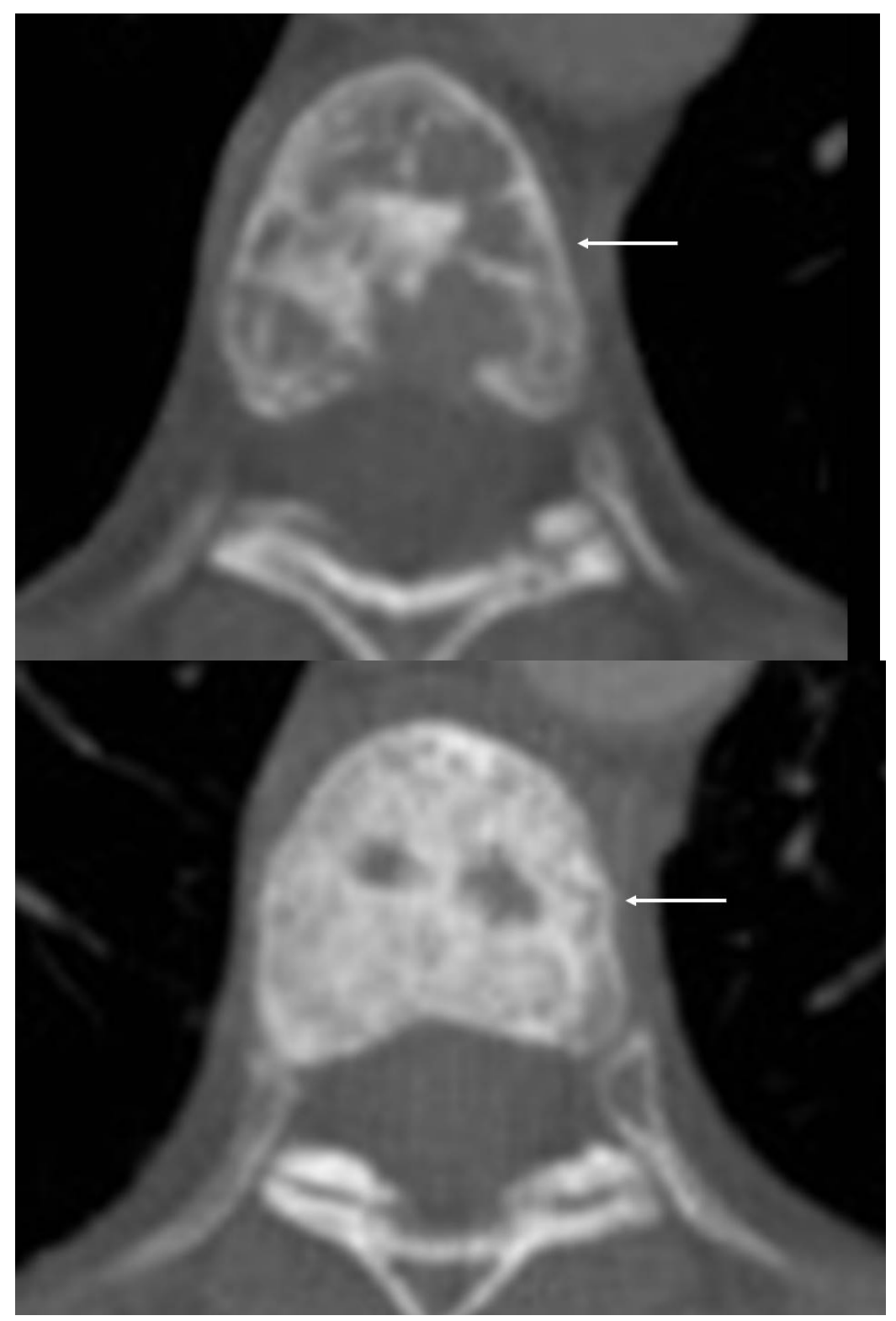

Figure 3: 59 year old woman with breast cancer. A) Axial contrast-enhanced CT at initial cancer diagnosis demonstrates a mixed lytic/blastic osseous metastasis in the T7 vertebral body (arrow). The average density is $330 \mathrm{HU}$ and the maximum density is $716 \mathrm{HU}$. B) Axial contrast-enhanced CT 13 months after initiation of chemotherapy demonstrates increased density of mixed lytic/blastic osseous metastasis in T7 (arrow). The average density is $859 \mathrm{HU}$ and the maximum density is 1107 HU. 


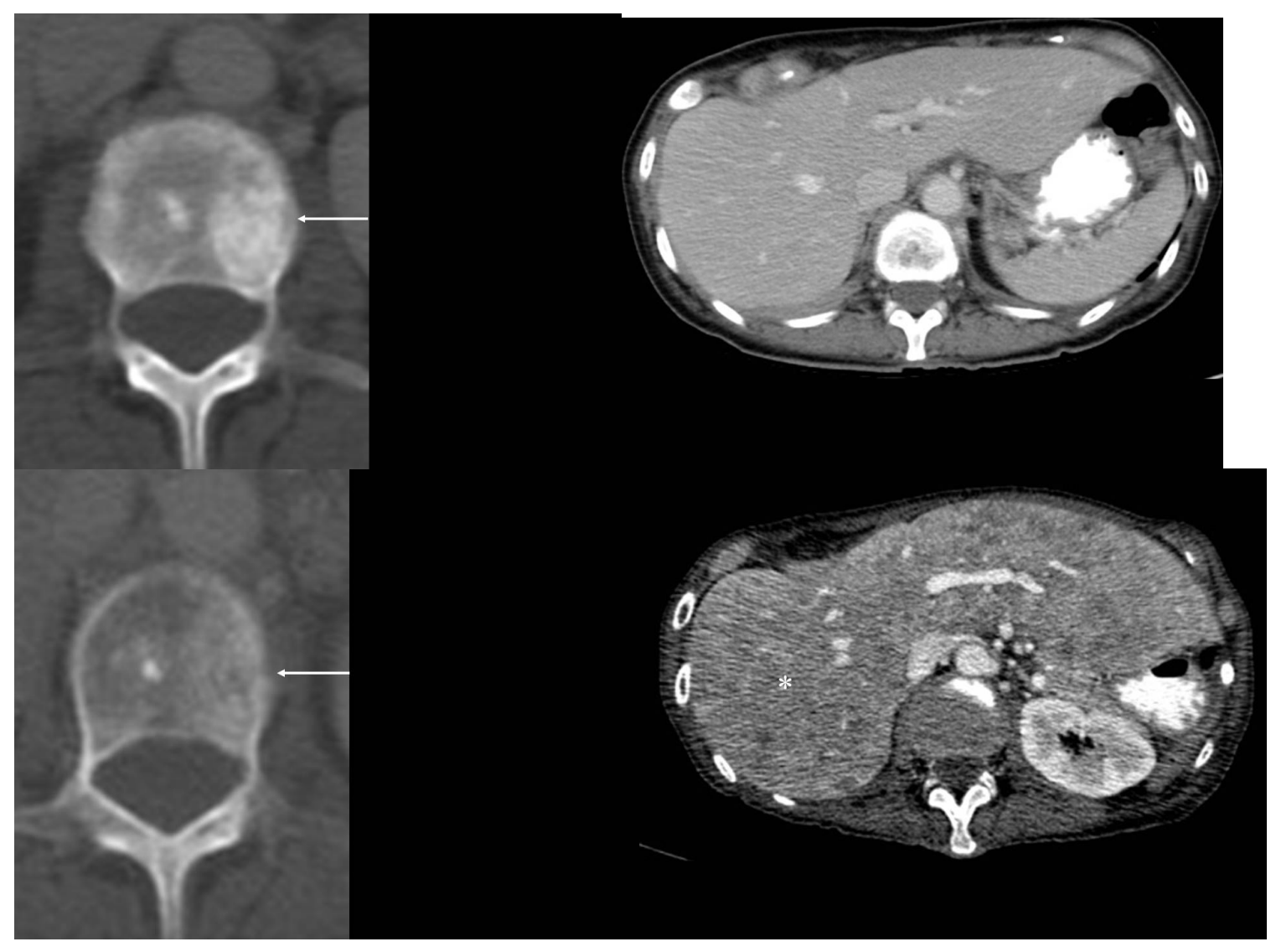

Figure 4: 65 year old woman with breast cancer. A) Axial contrast-enhanced CT at initial cancer diagnosis demonstrates a mixed lytic/blastic osseous metastasis in the L1 vertebral body (arrow). The average density is $542 \mathrm{HU}$ and the maximum density is $786 \mathrm{HU}$. B) Axial contrast-enhanced CT image at initial cancer diagnosis demonstrates a normal liver. C) Axial contrast-enhanced CT 16 months after initiation of chemotherapy demonstrates decreased density of mixed lytic/blastic osseous metastasis in L1 (arrow). The average density is $258 \mathrm{HU}$ and the maximum density is 528 HU. D) Axial contrast-enhanced CT 16 months after initiation of chemotherapy demonstrates new diffuse hepatic metastases $(*)$. 


\section{REFERENCES}

1. Coleman RE. Clinical features of metastatic bone disease and risk of skeletal morbidity. Clin. Cancer Res. 2006;12:6243s - 6249s.

2. Li S, Peng Y, Weinhandl ED, Blaes AH, Cetin K, Chia VM, et al. Estimated number of prevalent cases of metastatic bone disease in the US adult population. Clin Epidemiol. 2012;4:87-93.

3. Söderlund V. Radiological diagnosis of skeletal metastases. Eur Radiol. 1996;6:587-95.

4. Clemons M, Gelmon KA, Pritchard KI, Paterson AHG. Bone-targeted agents and skeletalrelated events in breast cancer patients with bone metastases: the state of the art. Curr Oncol. 2012;19:259-68.

5. Hamaoka T, Madewell JE, Podoloff DA, Hortobagyi GN, Ueno NT. Bone imaging in metastatic breast cancer. J. Clin. Oncol. 2004;22:2942-53.

6. Basu S, Alavi A. Defining co-related parameters between "metabolic" flare and "clinical", "biochemical", and "osteoblastic" flare and establishing guidelines for assessing response to treatment in cancer. Eur. J. Nucl. Med. Mol. Imaging. 2007;34:441-3.

7. Janicek MJ, Hayes DF, Kaplan WD. Healing flare in skeletal metastases from breast cancer. Radiology. 1994;192:201-4.

8. Lemieux J, Guimond J, Laberge F, St-Pierre C, Cormier Y. The bone scan flare phenomenon in non-small-cell lung cancer. Clin Nucl Med. 2002;27:486-9.

9. Vogel CL, Schoenfelder J, Shemano I, Hayes DF, Gams RA. Worsening bone scan in the evaluation of antitumor response during hormonal therapy of breast cancer. J. Clin. Oncol. 1995;13:1123-8.

10. Cosolo W, Morstyn G, Arkles B, Zimet AS, Zalcberg JR. Flare responses in small cell carcinoma of the lung. Clin Nucl Med. 1988;13:13-6.

11. Pollen JJ, Witztum KF, Ashburn WL. The flare phenomenon on radionuclide bone scan in metastatic prostate cancer. AJR Am J Roentgenol. 1984;142:773-6.

12. Pollen JJ, Shlaer WJ. Osteoblastic response to successful treatment of metastatic cancer of the prostate. AJR Am J Roentgenol. 1979;132:927-31.

13. DeMartini AL, Buzdar AU, Blumenschein GR. Osteoblastic metastatic disease as a therapeutic response to adjuvant chemotherapy in breast cancer. J Surg Oncol. 1983;23:32-4.

14. Amoroso V, Pittiani F, Grisanti S, Valcamonico F, Simoncini E, Ferrari VD, et al. Osteoblastic flare in a patient with advanced gastric cancer after treatment with pemetrexed and oxaliplatin: implications for response assessment with RECIST criteria. BMC Cancer. 2007;7:94. 
15. Dehdashti F, Flanagan FL, Mortimer JE, Katzenellenbogen JA, Welch MJ, Siegel BA. Positron emission tomographic assessment of "metabolic flare" to predict response of metastatic breast cancer to antiestrogen therapy. Eur J Nucl Med. 1999;26:51-6.

16. Stattaus J, Hahn S, Gauler T, Eberhardt W, Mueller SP, Forsting M, et al. Osteoblastic response as a healing reaction to chemotherapy mimicking progressive disease in patients with small cell lung cancer. Eur Radiol. 2009;19:193-200.

17. Messiou C, Cook G, Reid AHM, Attard G, Dearnaley D, de Bono JS, et al. The CT flare response of metastatic bone disease in prostate cancer. Acta Radiol. 2011;52:557-61.

18. Quattrocchi CC, Santini D, Dell'aia P, Piciucchi S, Leoncini E, Vincenzi B, et al. A prospective analysis of CT density measurements of bone metastases after treatment with zoledronic acid. Skeletal Radiol. 2007;36:1121-7.

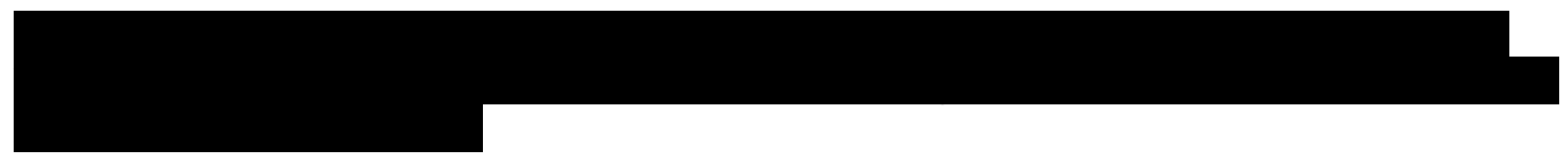

